\title{
Drug Resistance in the Microaerophilic Parasite Giardia lamblia
}

\author{
David Leitsch $^{1}$
}

Published online: 7 July 2015

(C) The Author(s) 2015. This article is published with open access at Springerlink.com

\begin{abstract}
The microaerophilic parasite Giardia lamblia is a causative agent of dysentery affecting hundreds of millions of people around the globe every year. The symptoms of the disease, commonly referred to as giardiasis, are diarrhea, nausea, and malabsorption. Treatment of giardiasis is exclusively based on chemotherapy with antigiardial drugs, including metronidazole, albendazole, and nitazoxanide. In this review, all drugs currently used in the treatment of Giardia infections are discussed with a special emphasis on treatment failure and drug resistance.
\end{abstract}

Keywords Giardia lamblia · Dysentery · Chemotherapy · Drug resistance

\section{Introduction}

Giardia lamblia (syn. intestinalis, duodenalis) is a worldwide occurring protist parasite that causes a form of dysentery commonly referred to as giardiasis [1]. Although Giardia infections frequently present without symptoms and are often selflimiting, severe gastrointestinal symptoms such as diarrhea, nausea, bloating, or malabsorption can also ensue. Postinfection symptoms such as lactose intolerance [2] or irritable

iThenticate: $6 \%$

This article is part of the Topical Collection on Protozoa (Giardia)

\section{David Leitsch}

david.leitsch@vetsuisse.unibe.ch

1 Institute of Parasitology, Vetsuisse Faculty, University of Berne, Länggass-Strasse 122, CH-3012 Berne, Switzerland bowel syndrome are not rare [3]. With as much as $33 \%$ of the population in developing countries having a record of giardiasis [4], G. lamblia is considered to be the most common protist parasite of the human gastrointestinal tract. It preferably colonizes the small intestine and has a two-staged life cycle. The acid-resistant, metabolically widely inactive cyst is ingested by the host and passes through the stomach into the small intestine. There it excysts and develops into the trophozoite which is the actively feeding and pathogenic stage. The trophozoite either moves freely in the lumen or attaches to the intestinal mucosa. A given proportion of the trophozoite population undergoes development into cysts which are excreted in the feces and contaminate water or food. Upon ingestion of cysts by another host, a new cycle of infection can commence.

As no prophylaxis against Giardia infections is available, countermeasures are limited to chemotherapy of established infections. Fortunately, a comparably large selection of drugs is available for the treatment of giardiasis. The most commonly prescribed drugs are the 5-nitroimidazoles metronidazole and tinidazole and the benzimidazole albendazole (Fig. 1). Other drugs used are quinacrine, nitazoxanide, furazolidone, mebendazole, paromomycin, and bacitracin zinc (Fig. 1). Auranofin, an approved antirheumatic [5•], and the orphan drug fumagillin $\left[6^{\bullet}\right]$ are highly effective against $G$. lamblia and might be introduced as antigiardial drugs in the near future.

In most of the cases (about $90 \%$ ), treatment regimens with either metronidazole or albendazole alone are effective, but recalcitrant giardiasis, sometimes due to drug resistance, is not rare [7]. In such cases, combination therapy regimens of metronidazole and albendazole or quinacrine are highly effective $[8,9]$. However, it cannot be denied that drug resistance does occur in G. lamblia, which is a matter of concern due to the frequent occurrence of this parasite. 
This review will give an overview over the most common drugs in use against $G$. lamblia, occurrence and mechanisms of drug resistance, and other circumstances that may lead to the failure of treatment.

\section{Antigiardial Drugs}

The arsenal of antigiardial drugs is fortunately rather large although only few drugs are used in daily practice. In fact, in some countries, e.g., Norway [10], only metronidazole is approved for the treatment of giardiasis. In addition to the abovementioned compounds (Fig. 1), pentamidines [11], chloroquine, DL-propanolol, propolis, and ozonized sunflower oil have been successfully tested against G. lamblia in vitro and in vivo [12].

\section{Metronidazole, Tinidazole, and Ornidazole}

Metronidazole (Fig. 1) is a 5-nitroimidazole drug which was specifically developed in the late 1950s against another microaerophilic parasite, Trichomonas vaginalis [13]. Soon after its discovery, metronidazole was also successfully tested against numerous other anaerobic and microaerophilic pathogens, including G. lamblia [14], and is nowadays listed among the "essential medicines" by the WHO. Metronidazole is, in fact, a prodrug which needs to be reduced at its nitro group in order to become toxic [15]. Due to the very low redox potential of metronidazole [16], this only quantitatively occurs in microaerophilic and anaerobic organisms which have a strongly reductive physiology [17]. In the 13th report on carcinogens issued by the NIH [18], metronidazole has been classified as carcinogenic because it causes tumors in mice when administered in very high doses. However, no link between metronidazole treatment and cancer has so far been observed in humans despite its frequent use. Thus, although inconvenient side effects are regularly reported, metronidazole is a rather safe drug in humans and animals. Treatment is carried out for 5-10 days with one or two doses per day [12].

Metronidazole damages DNA in microaerophiles and anaerobes [19], obviously by introducing double strand breaks [20•]. In addition, metronidazole binds to free thiols, such as cysteine, which has a similar role in many microaerophilic parasites as glutathione has in mammalian cells [21-24]. Metronidazole also forms covalent adducts with cysteines in proteins. Specifically, metronidazole targets the redox enzyme thioredoxin reductase in Entamoeba histolytica, Trichomonas vaginalis, and G. lamblia and inhibits the enzyme's function as a disulfide reductase [21, 22, 24]. All these events result in severe oxidative stress. This is further corroborated by the observation that cysteine, added to the growth medium, protects Giardia from metronidazole [25]. In G. lamblia, metronidazole also leads to the degradation of elongation factor $1-\gamma$ (EF1- $\gamma)$, an enzyme involved in protein translation [23]. The mode of action of other 5-nitroimidazoles, e.g., tinidazole and ornidazole, is very likely to be identical [21]. However, tinidazole and ornidazole are more efficacious than metronidazole because they have considerably longer serum half-lives than metronidazole [12] and can be administered as single doses of 1 or $2 \mathrm{~g}$. As a result, they have a better patient compliance than metronidazole.

\section{Albendazole and Mebendazole}

The benzimidazole drug albendazole (Fig. 1) was approved in 1983 for the treatment of helminth infections and was soon found to be efficacious against G. lamblia as well [26-28]. When given in single $400 \mathrm{mg}$ doses for 5 days, it is equally
1<smiles>Cc1ncc([N+](=O)[O-])n1CCO</smiles>

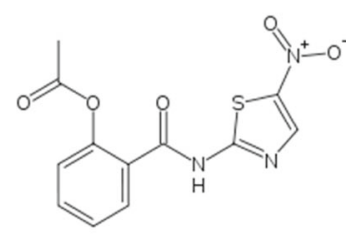

4
2<smiles>CCCSc1ccc2[nH]c(NC(=O)OC)nc2c1</smiles>

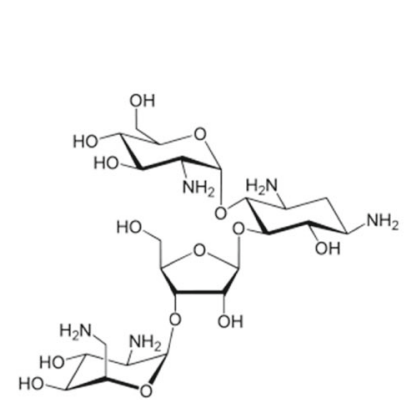

5
3<smiles>O=C1OCCN1/N=C/c1ccc([N+](=O)[O-])o1</smiles>

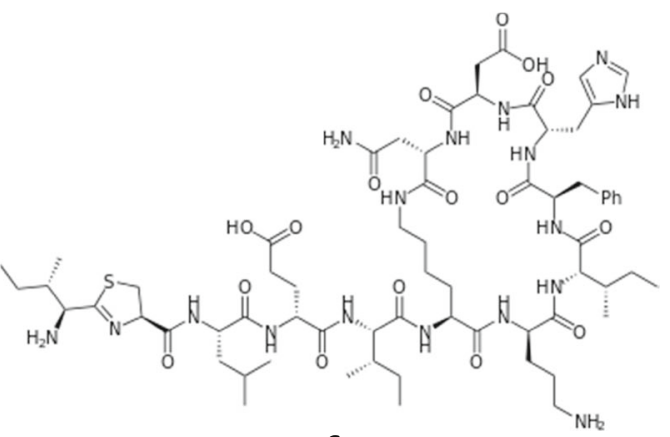

6

Fig. 1 Antigiardial drugs: metronidazole (1), albendazole (2), furazolidone (3), nitazoxanide (4), paromomycin (5), and bacitracin (6). All images are taken from wikipedia.org 
effective as metronidazole but has fewer side effects because it is poorly absorbed in the human gut [29]. Consequently, albendazole therapy against giardiasis is an alternative to metronidazole therapy. Another benzimidazole, mebendazole, was also found to be effective against G. lamblia [27]. Treatment courses with mebendazole, however, have been reported to be variably effective [30-33]. For both, albendazole and mebendazole, teratogenic effects in rats were reported [12].

One confirmed target of benzimidazoles is $\beta$-tubulin [27, 3], a major component of the cytoskeleton in G. lamblia [35]. Albendazole and mebendazole bind very efficiently to $\beta$ tubulin in susceptible organisms [36], including G. lamblia, thereby leading to the inhibition of cytoskeleton polymerization and, consequently, to severe structural defects [37].

\section{Nitazoxanide}

The nitrothiazolide compound nitazoxanide (Fig. 1) was first described as antihelmintic [38] but later also found to be active against a range of other parasites including Giardia lamblia [39]. In 2004, it was approved in the USA for the pediatric treatment of giardiasis. As is the case with 5-nitroimidazoles, nitazoxanide has to be reduced at the nitro group for activity in Giardia [40]. Nitazoxanide is usually prescribed for 3 days and well tolerated because it is poorly absorbed in the intestine [12]. No evidence for any mutagenic or teratogenic activity of nitazoxanide has been found so far.

The mode of action of nitazoxanide is very likely to be multifactorial. Nitazoxanide strongly inhibits the pyruvate decarboxylating enzyme pyruvate:ferredoxin oxidoreductase (PFOR), an enzyme of central physiological importance in G. lamblia [41]. However, nitazoxanide also inhibits other enzymes, such as nitroreductase 1 [42], a presumptive quinone reductase [43], and compromises the integrity of the cell by causing lesions in the ventral cell membrane and inducing vacuolization [40].

\section{Quinacrine}

The acridine drug quinacrine (Fig. 1) was originally introduced as an antimalarial but also used for the treatment of giardiasis after the Second World War [34]. The drug is very effective but must be given over 5-10 days and frequently causes side effects such as nausea or discoloration of the skin. Its mode of action has been scarcely studied, but it was found to inhibit nucleic acid synthesis [44] In G. lamblia, however, no evidence was found that quinacrine accumulates in the nucleus [45]. As is the case with metronidazole, quinacrine toxicity is counteracted by cysteine [25], suggesting that the drug's mode of action includes induction of oxidative stress. Currently, quinacrine is only used as a second-line therapeutic in combination with metronidazole or albendazole.

\section{Paromomycin}

Effectiveness of the aminoglycoside paromomycin (Fig. 1) against G. lamblia was first reported in 1989 [46]. The efficacy of the drug, however, greatly varies among laboratories $[46,47]$, and in one instance, no effect of paromomycin on G. lamblia was observed at all [48]. Paromomycin has been rarely used in the treatment of giardiasis but its particular advantage is that it is practically not absorbed by the intestine, rendering it safe for use during pregnancy [34]. It is effective as a second-line drug in combination with metronidazole [49].

\section{Furazolidone}

Like the 5-nitroimidazoles and nitazoxanide, the nitrofuran furazolidone (Fig. 1) is a prodrug whose nitro group must be reduced in order to be rendered active $[50,51]$. It has a higher redox potential than 5-nitroimidazoles and is therefore more efficiently reduced in microaerophilic parasites [22, 52]. The reduced intermediates of furazolidone likely damage cell constituents such as DNA and proteins [34]. A related nitrofuran, nifurtimox, was reported to bind to thiol groups [53] and to lower free thiol concentrations in Trypanosoma cruzi [54].

Furazolidone is clinically highly effective when administered for 7-10 days, but shorter courses yield lower cure rates. One great advantage of furazolidone is its availability as a liquid suspension which has a higher compliance with children.

\section{Bacitracin Zinc}

The polypeptide antibiotic bacitracin (Fig. 1) was found to be effective against $G$. lamblia in 1994 [55] and was even several-fold more so in combination with zinc. To date, only one clinical trial for treatment of giardiasis with bacitracin zinc was performed [56]. Although bacitracin zinc treatment was effective, it had to be continued for 10 days which negatively affects patient compliance [34].

\section{Treatment Failure and Drug Resistance in G. lamblia}

Most clinical studies on chemotherapy of giardiasis demonstrate that, regardless of the drug used, cure rates are normally below $100 \%$. Apart from drug resistance, other factors can also be responsible for treatment failure, such as reinfection, insufficient amounts of drug administered, immunosuppression, or sequestration in the gallbladder or the pancreas [9]. If two or more courses of treatment with a given drug are unsuccessful, it is recommended to either use another drug alone or in combination with the first drug [9, 34]. Most of the refractory cases can be ultimately cured with the arsenal of antigiardial drugs available. This is very well illustrated in a 
careful study on a chosen treatment regime during an outbreak of giardiasis in Norway. A treatment ladder was applied in order to minimize the number of patients remaining uncured after treatment [8]. Thirty-eight individuals out of more than 1200 treated in total were not cured from giardiasis after one to three courses of metronidazole therapy. As a next step, the refractory cases were treated with a combination of metronidazole and albendazole, resulting in the cure of 30 patients. The eight patients, neither responding to metronidazole nor to albendazole, were treated with paromomycin, resulting in the cure of four. The remaining four patients were finally cured after 3 weeks of treatment with a combination of quinacrine and high doses of metronidazole. Importantly, the combination of metronidazole and quinacrine was also found by others to be effective in eliminating refractory $G$. lamblia infections $[9,57]$.

It is important to note that G. lamblia isolated from patients with refractory giardiasis do not always display drug resistance in vitro [57], suggesting some physiological influence of the human host on the success of a given chemotherapy. It is, therefore, important to rule out that people with recurrent symptoms have not been re-infected and that they are not suffering from lactose intolerance or irritable bowel syndrome which frequently evolves after giardiasis $[2,3]$.

No reports or studies on resistance to the more rarely used antigiardial drugs, bacitracin zinc and paromomycin, have been published, but resistance in G. lamblia to 5nitroimidazoles, albendazole, nitazoxanide, quinacrine, and furazolidone has been studied to varying extent.

\section{Resistance to Metronidazole and Other 5-nitroimidazoles}

Metronidazole resistance has been intensely studied in microaerophilic and anaerobic pathogens, including G. lamblia. Indeed, resistant Giardia strains have been repeatedly isolated from patients with refractory giardiasis [58, 59]. In addition, resistance to metronidazole and other 5nitroimidazoles is relatively easy to induce in the laboratory by exposing Giardia to incremental doses of drug or to UV light [7, 42, 60-62]. Eventually, tolerance to metronidazole can be increased to more than the 100 -fold the $\mathrm{IC}_{50}$ of the drug in sensitive isolates [61].

The mechanisms of metronidazole resistance have been widely discussed throughout the last 40 years, but the observations made are often conflicting and difficult to put into perspective. Two factors that have been understood as being central for the reduction, i.e., activation of 5-nitroimidazoles, are pyruvate ferredoxin oxidoreductase (PFOR) and its cofactor ferredoxin which are almost always present in microaerophilic and anaerobic organisms [63]. As shown in several organisms, including Giardia, ferredoxin is reduced by PFOR and can transfer an electron to the nitro group of metronidazole [16, 64-66]. In accordance, slightly reduced
PFOR activities were measured in Giardia stocks with reduced sensitivity to metronidazole [67] and some metronidazole-resistant strains generated in the laboratory, e.g., BRIS/83/HEPU106-2ID ${ }_{10}$, have only remnant PFOR activity $[68,69]$. Further, a knock-down of PFOR expression using hammerhead ribozymes rendered Giardia resistant to metronidazole [70]. In contrast, however, metronidazoleresistant cell lines with an intact $\mathrm{PFOR} /$ ferredoxin pathway, e.g., BRIS/87/HEPU/713-M3, were described [69]. Moreover, Giardia cell lines resistant to $\mathrm{C} 17$, a secondgeneration 5-nitroimidazole [71], are highly cross-resistant to metronidazole but have fully functional PFOR and ferredoxin [69]. Thus, inactivation of the PFOR/ferredoxin pathway is not a prerequisite for 5-nitromidazole resistance. In a series of research papers, it was shown that nitroreductase 1 and 2 could have an important role in the metabolism of metronidazole in Giardia. Interestingly, nitroreductase 1 can activate metronidazole to reactive metabolites [72], whereas nitroreductase 2 has, conversely, a protective effect, possibly through fully reducing the drug's nitro group with six electrons to a non-toxic amino group [73•]. In accordance with this notion, expression of nitroreductase 1 was found to be downregulated in metronidazole-resistant laboratory cell lines $[72,73 \bullet]$, whereas nitroreductase 2 was found to be upregulated [73•]. Furthermore, overexpression of nitroreductase 2 renders Giardia more tolerant to metronidazole [73•]. Expression of thioredoxin reductase (TrxR) [21, 22, 69], however, i.e., another factor that can reduce 5-nitroimidazoles, was not found to be affected in metronidazole-resistant Giardia cell lines [69].

In any case, it is certain that reduced metronidazole sensitivity in clinical Giardia isolates on the one hand and fully developed metronidazole resistance induced in the laboratory on the other are caused by different underlying mechanisms. Metronidazole-resistant cell lines generated in the lab do hardly establish infections in mice, indicating that the physiological adaptations necessary to tolerate high doses of metronidazole have high fitness costs [74]. Also in another microaerophilic parasite, Trichomonas vaginalis, metronidazole resistance in clinical isolates is fundamentally different from metronidazole resistance generated in the laboratory [75-78]. In metronidazole-resistant clinical T. vaginalis isolates, no downregulation or inactivation of factors that reduce 5-nitroimidazoles can be observed [23, 76, 79]. Instead, the oxygen scavenging capability is impaired [76], leading to higher intracellular oxygen concentrations. Since oxygen quickly re-oxidizes nitroradical anions to the non-toxic prodrug, these strains are highly resistant to metronidazole if oxygen is present [80] but normally susceptible to the drug when oxygen levels are low [75]. Presumably, downregulation of flavin reductase 1 [81], which reduces oxygen to hydrogen peroxide by using FMN and NADPH as cofactors, is a key event in the development of clinical metronidazole 
resistance in T. vaginalis. NADPH-dependent reduction of oxygen via FMN can also be observed in G. lamblia [68] but is catalyzed by another, yet undescribed, enzyme because T. vaginalis flavin reductase 1 has no homologue in the G. lamblia genome. Confusingly, this enzyme activity is downregulated in metronidazole-resistant G. lamblia laboratory cell lines [69] but strongly upregulated in clinical isolates with reduced metronidazole sensitivity [68]. Thus, for all the research efforts of the last decades, our understanding of metronidazole resistance in G. lamblia is still incomplete at best.

\section{Resistance to Nitazoxanide}

Although nitazoxanide resistance has not been observed yet in the clinic, it can be induced in the laboratory [42]. In one study, a nitazoxanide-resistant cell line was strongly crossresistant to metronidazole, whereas a cell line with induced metronidazole resistance was fully susceptible to nitazoxanide [42], indicating that cross resistance between both drugs is not necessarily reciprocal. In another study, however, laboratory cell lines, adapted to high concentrations of metronidazole, also displayed a similar level of resistance towards nitazoxanide [74]. An expression study on the nitazoxanideresistant cell line showed several protein chaperones such as Hsp70, Hsp90, and Cpn60, and several surface antigens to be upregulated in expression [82]. Levels of PFOR were practically unaltered in nitazoxanide-resistant cell lines [42], but nitroreductase 1 was found downregulated [72]. Overexpression of nitroreductase 2, however, has no protective effect in Giardia against nitazoxanide [73•]. In summary, resistance mechanisms against metronidazole and nitazoxanide do partially overlap but are not identical.

\section{Resistance to Albendazole}

Resistance to albendazole has been repeatedly observed in clinical isolates [58, 59] and in the laboratory [62, 83-85]. Indeed, Giardia can be adapted to concentrations of albendazole that are about 1000 -fold higher than the $\mathrm{IC}_{50}$ of the drug in susceptible stocks [85]. In helminths, benzimidazole resistance is usually conferred by mutations in the $\beta$ tubulin gene, preferably at amino acid positions 167 and 200 [86]. In Giardia, however, conflicting observations have been made in this regard. In one study, an altered amino acid sequence of $\beta$-tubulin upon extended exposure to increasing concentrations of albendazole was identified [84], whereas others found no alterations in the sequence [45, 62]. Instead, chromosomal rearrangements, cytoskeletal aberrations [45], and the altered expression of several genes, including a VSP-like protein [62], constituents of the ventral disk ( $\alpha 2$ giardin) or various enzymes such as NADH oxidase and triosephosphate isomerase [85], were found in albendazole- resistant cell lines. Interestingly, also PFOR was reported to be upregulated in albendazole-resistant cell lines [62]. The implications of these findings are still unclear as yet, but they suggest that benzimidazoles probably target a more diverse group of molecules in G. lamblia than in helminths.

\section{Resistance to Furazolidone}

Based on electron paramagnetic resonance (EPR) spectra, the enzyme NADH oxidase was suggested to be an activator of furazolidone in $G$. lamblia by donating an electron to the drug's nitro group [52]. Reduction of the nitro group gives rise to a nitroradical anion which is believed to be the actual toxic agent. However, although resistance to furazolidone can be induced in vitro [61], no correlation between NADH oxidase activity and furazolidone resistance has been reported as yet. Also, PFOR activity was not altered in furazolidone-resistant Giardia [15]. In fact, due to the relatively high reduction potential of nitrofurans, at least in comparison with nitroimidazoles, quantitative reduction of furazolidone might already take place as soon as reduced flavin (either free or bound to proteins as cofactors) is present in the cell [87].

In clinical isolates which demonstrate reduced sensitivity to furazolidone, thiol-dependent peroxidase and reductase activities were reported to be increased [67]. These activities can be attributed most likely to peroxiredoxin and thioredoxin reductase, respectively. It is reasonable to assume that higher levels of these enzymes render Giardia more tolerant to reactive oxygen species which are generated by redox cycling of furazolidone nitroradical anions. Still, it is questionable whether these enhanced enzyme activities can account for the far more pronounced resistance induced in vitro [61]. Importantly, strains with previously induced furazolidone resistance can be adapted to high concentrations of quinacrine much easier than wild type, suggesting the existence of a common drug export mechanism [45]. However, Giardia laboratory cell lines with metronidazole resistance also tolerate more furazolidone [74], albeit to a far lesser degree as compared to metronidazole.

\section{Resistance to Quinacrine}

Only few data on quinacrine resistance in G. lamblia are available. However, in a careful study resistance to quinacrine was gradually induced in vitro in several strains [45]. Eventually, resistant cell lines were able to grow at concentrations about 50-fold higher than the normal $\mathrm{IC}_{50}$ [88]. Fluorescence analysis suggested that the drug is excluded from resistant G. lamblia [45]. 


\section{Conclusions}

It is unlikely that the management of giardiasis will be compromised in the future by a lack of treatment options. Although treatment failures and drug resistance in Giardia can be problematic, a comparably large number of effective drugs are available, and combination therapy is almost always successful. Moreover, promising novel treatment options have been presented recently, such as formononetin $[89,90]$, auranofin [5•] and fumagillin [6•], and natural products with antigiardial activity have remained an as yet untapped source [91].

Acknowledgements David Leitsch is funded by the Austrian Science Fund (FWF): project J3492.

\section{Compliance with Ethics Guidelines}

Conflict of Interest David Leitsch declares that he has no conflict of interest.

Human and Animal Rights and Informed Consent This article does not contain any studies with human or animal subjects performed by any of the authors.

Open Access This article is distributed under the terms of the Creative Commons Attribution 4.0 International License (http:// creativecommons.org/licenses/by/4.0/), which permits unrestricted use, distribution, and reproduction in any medium, provided you give appropriate credit to the original author(s) and the source, provide a link to the Creative Commons license, and indicate if changes were made.

\section{References}

Papers of particular interest, published recently, have been highlighted as:

- Of importance

1. Buret AG. Pathophysiology of enteric infections with Giardia duodenalis. Parasite. 2008;15:261-5.

2. Farthing MJ. Giardiasis. J Pediatr Gastroenterol Nutr. 1997;24:7988.

3. Halliez MC, Buret AG. Extra-intestinal and long term consequences of Giardia duodenalis infections. World J Gastroenterol. 2013; 19:8974-85.

4. Centers for Disease Control and Prevention. Parasites - Giardia. http://www.cdc.gov/parasites/giardia. Accessed April 102015.

5. Tejman-Yarden N, Miyamoto Y, Leitsch D, Santini J, Debnath A, Gut J, et al. Auranofin, a reprofiled drug, is effective against metronidazole-resistant Giardia lamblia. Antimicrob Agents Chemother. 2013;57:2029-35. Description of auranofin as a promising novel antigiardial drug.

6. Kulakova L, Galkin A, Chen CZ, Southall N, Marugan JJ, Zheng W, et al. Discovery of novel antigiardiasis drug candidates. Antimicrob Agents Chemother. 2014;58:7303-11. Description of fumagillin as a promising novel antigiardial drug.
7. Tejman-Yarden N, Eckman L. New approaches to the treatment of giardiasis. Curr Opin Infect Dis. 2011;24:451-6.

8. Mørch K, Hanevik K, Robertson LJ, Strand EA, Langeland N. Treatment-ladder and genetic characterisation of parasites in refractory giardiasis after an outbreak in Norway. J Infect Dis. 2008;56: $268-73$.

9. Nash TE. Treatment of Giardia lamblia infections. Pediatr Infect Dis J. 2001;20:193-5.

10. Wensaas KA, Langeland N, Rortveit G. Prevalence of recurring symptoms after infection with Giardia lamblia in a non-endemic area. Scand J Prim Health. 2009;27:12-7.

11. Bell CA, Cory M, Fairley TA, Hall JE, Tidwell RR. Structureactivity relationships of pentamidine analogs against Giardia lamblia and correlation of antigiardial activity with DNA-binding affinity. Antimicrob Agents Chemother. 1991;35:1099-107.

12. Escobedo AA, Cimerman S. Giardiasis: a pharmacotherapy review. Expert Opin Pharmacother. 2007;8:1885-902.

13. Cosar C, Julou L. The activity of 1-(2-hydroxyethyl)-2-methyl-5nitroimidazole (R. P. 8823) against experimental Trichomonas vaginalis infections. Ann Inst Pasteur (Paris). 1959;96:238-41.

14. Schneider J. Treatment of giardiasis (lambliasis) by metronidazole. Bull Soc Pathol Exot Filiales. 1961;54:84-95.

15. Upcroft P, Upcroft JA. Drug targets and mechanisms of resistance in the anaerobic protozoa. Clin Microbiol Rev. 2001;14:150-64.

16. Yarlett N, Gorell TE, Marczak R, Müller M. Reduction of nitroimidazole derivatives by hydrogenosomal extracts of Trichomonas vaginalis. Mol Biochem Parasitol. 1985;14:29-40.

17. Samuelson J. Why metronidazole is active against both bacteria and parasites. Antimicrob Agents Chemother. 1999;43:1533-41.

18. Centers for Disease Control and Prevention. Report on carcinogens, 13th edition. Metronidazole. http://ntp.niehs.nih.gov/ntp/roc/ content/profiles/metronidazole.pdf. Accessed April 10th 2015.

19. Edwards DI. Nitroimidazole drugs - action and resistance mechanisms. I. Mechanisms of action. J Antimicrob Chemother. 1993;31: 9-20.

20. Uzlikova M, Nohynkova E. The effect of metronidazole on the cell cycle and DNA in metronidazole-susceptible and -resistant Giardia cell lines. Mol Biochem Parasitol. 2014;198:75-81. This study proves that metronidazole damages DNA in Giardia.

21. Leitsch D, Kolarich D, Wilson IBH, Altmann F, Duchêne M. Nitroimidazole action in Entamoeba histolytica: a central role for thioredoxin reductase. PLoS Biol. 2007;5:1820-34.

22. Leitsch D, Kolarich D, Binder M, Stadlmann J, Altmann F, Duchêne M. Trichomonas vaginalis: metronidazole and other nitroimidazole drugs are reduced by the flavin enzyme thioredoxin reductase and disrupt the cellular redox system. Implications for nitroimidazole toxicity and resistance. Mol Microbiol. 2009;72: 518-36.

23. Leitsch D, Schlosser S, Burgess A, Duchêne M. Nitroimidazole drugs vary in their mode of action in the human parasite Giardia lamblia. Internat J Parasitol Drugs Drug Resis. 2012;2:166-70.

24. Williams CF, Lloyd D, Kolarich D, Alagesan K, Duchêne M, Cable $\mathrm{J}$, et al. Disrupted intracellular redox balance of the diplomonad fish parasite Spironucleus vortens by 5-nitroimidazoles and garlicderived compounds. Vet Parasitol. 2012;190:62-73.

25. Gillin FD, Diamond LS. Inhibition of clonal growth of Giardia lamblia and Entamoeba histolytica by metronidazole, quinacrine, and other antimicrobial agents. J Antimicrob Chemother. 1981;8: 305-16.

26. Meloni BP, Thompson RC, Reynoldson JA, Seville P. Albendazole: a more effective antigiardial agent in vitro than metronidazole or tinidazole. Trans R Soc Trop Med Hyg. 1990;84:375-9.

27. Edlind TD, Hang TL, Chakraborty PR. Activity of the anthelmintic benzimidazoles against Giardia lamblia in vitro. J Infect Dis. 1990;162:1408-11. 
28. Reynoldson JA, Thompson RC, Meloni BP. In vivo efficacy of albendazole against Giardia duodenalis in mice. Parasitol Res. 1991;77:325-8.

29. Solaymani-Mohammadi S, Genkinger JM, Loffredo CA, Singer SM. A meta-analysis of the effectiveness of albendazole compared with metronidazole as treatments for infections with Giardia duodenalis. PLoS Negl Trop Dis. 2010;4, e682.

30. di Martino L, Nocerino A, Mantovani MP. Mebendazole in giardial infections: confirmation of the failure of this treatment. Trans R Soc Trop Med Hyg. 1991;85:557-8.

31. Rousham EK. An increase in Giardia duodenalis infection among children receiving periodic Anthelmintic treatment in Bangladesh. J Trop Pediatr. 1994;40:329-33.

32. Canete R, Escobedo AA, Gonzalez ME, Almirall P. Randomized clinical study of five days apostrophe therapy with mebendazole compared to quinacrine in the treatment of symptomatic giardiasis in children. World J Gastroenterol. 2006;12:6366-70.

33. Almirall P, Escobedo AA, Ayala I, Alfonso M, Salazar Y, Cañete R, et al. Mebendazole compared with secnidazole in the treatment of adult giardiasis: a randomised, no-inferiority, open clinical trial. J Parasitol Res. 2011;2011:636857.

34. Gardner TB, Hill DR. Gardner and Hill Treatment of giardiasis. Clin Microbiol Rev. 2001;14:114-28.

35. Holberton DV, Ward AP. Isolation of the cytoskeleton from Giardia. Tubulin and a low-molecular-weight protein associated with microribbon structures. J Cell Sci. 1981;47:139-66.

36. MacDonald LM, Armson A, Thompson AR, Reynoldson JA. Characterisation of benzimidazole binding with recombinant tubulin from Giardia duodenalis, Encephalitozoon intestinalis, and Cryptosporidium parvum. Mol Biochem Parasitol. 2004;138:8996.

37. Chavez B, Cedillo-Rivera R, Martinez-Palomo A. Giardia lamblia: ultrastructural study of the in vitro effect of benzimidazoles. J Protozool. 1992;39:510-5.

38. Gilles HM, Hoffman PS. Treatment of intestinal parasitic infections: a review of nitazoxanide. Trends Parasitol. 2002;18:95-7.

39. Adagu IS, Nolder D, Warhurst D, Rossignol JF. In vitro activity of nitazoxanide and related compounds against isolates of Giardia intestinalis, Entamoeba histolytica and Trichomonas vaginalis. $\mathrm{J}$ Antimicrob Chemother. 2002;49:103-11.

40. Müller J, Rühle G, Müller N, Rossignol JF, Hemphill A. In vitro effects of thiazolides on Giardia lamblia WB clone C6 cultured axenically and in coculture with Caco2 cells. Antimicrob Agents Chemother. 2006;50:162-70.

41. Hoffman PS, Sisson G, Croxen MA, Welch K, Harman WD, Cremades N, et al. Antiparasitic drug nitazoxanide inhibits the pyruvate oxidoreductases of Helicobacter pylori, selected anaerobic bacteria and parasites, and Campylobacter jejuni. Antimicrob Agents Chemother. 2007;51:868-76.

42. Müller J, Wastling J, Sanderson S, Müller N, Hemphill A. A novel Giardia lamblia nitroreductase, GINR1, interacts with nitazoxanide and other thiazolides. Antimicrob Agents Chemother. 2007;51: 1979-86.

43. Müller J, Rout S, Leitsch D, Vaithilingam J, Hehl A, Norbert MN. Comparative characterisation of two nitroreductases from Giardia lamblia as potential activators of nitro compounds. Int J Parasitol Drugs Drug Resist. 2015;5:37-43.

44. Ehsanian R, Van Waes C, Feller SM. Beyond DNA binding-a review of the potential mechanisms mediating quinacrine's therapeutic activities in parasitic infections, inflammation, and cancers. Cell Commun Signal. 2011;9:13.

45. Upcroft JA, Campbell RW, Upcroft P. Quinacrine-resistant Giardia duodenalis. Parasitology. 1996;112:309-13.

46. Edlind TD. Susceptibility of Giardia lamblia to aminoglycoside protein synthesis inhibitors: correlation with rRNA structure. Antimicrob Agents Chemother. 1989;33:484-8.
47. Yu DC, Wang AL, Wang CC. Stable coexpression of a drugresistance gene and a heterologous gene in an ancient parasitic protozoan Giardia lamblia. Mol Biochem Parasitol. 1996;83:81-91.

48. Boreham PF, Phillips RE, Shepherd RW. A comparison of the invitro activity of some 5-nitroimidazoles and other compounds against Giardia intestinalis. J Antimicrob Chemother. 1985;16:589-95.

49. Nash TE. Unraveling how Giardia infections cause disease. J Clin Invest. 2013;123:2346-7.

50. Tatsumi K, Yamada H, Yoshimura H, Kawazoe Y. Metabolism of furazolidone by milk xanthine oxidase and rat liver $9000 \mathrm{~g}$ supernatant: formation of a unique nitrofuran metabolite and an aminofuran derivative. Arch Biochem Biophys. 1981;208:167-74.

51. Upcroft JA, Upcroft P, Boreham PF. Drug resistance in Giardia intestinalis. Int J Parasitol. 1990;20:489-96.

52. Brown DM, Upcroft JA, Upcroft P. A $\mathrm{H}_{2} \mathrm{O}$-producing NADH oxidase from the protozoan parasite Giardia duodenalis. Eur J Biochem. 1996;241:155-61.

53. Díaz EG, Montalto de Mecca M, Castro JA. Reactions of nifurtimox with critical sulfhydryl-containing biomolecules: their potential toxicological relevance. J Appl Toxicol. 2004;24:189-95.

54. Maya JD, Repetto Y, Agosín M, Ojeda JM, Tellez R, Gaule C, et al. Effects of nifurtimox and benzonidazole upon glutathione and trypanothione content in epimastigote, trypomastigote and amastigote forms of Trypanosoma cruzi. Mol Biochem Parasitol. 1997;86:101-6.

55. Andrews BJ, Panitescu D, Jipa GH, Vasile-Bugarin AC, Vasiliu RP, Ronnevig JR. Chemotherapy for giardiasis: randomized clinical trial of bacitracin, bacitracin zinc, and a combination of bacitracin zinc with neomycin. Am J Trop Med Hyg. 1995;52:318-21.

56. Andrews BJ, Mylvaganam H, Yule A. Sensitivity of Trichomonas vaginalis, Tritrichomonas foetus and Giardia intestinalis to bacitracin and its zinc salt in vitro. Trans R Soc Trop Med Hyg. 1994;88:704-6.

57. Smith PD, Gillin FD, Spira WM, Nash TE. Chronic giardiasis: studies on drug sensitivity, toxin production, and host immune response. Gastroenterology. 1982;83:797-803.

58. Farbey MD, Reynoldson JA, Thompson RC. In vitro drug susceptibility of 29 isolates of Giardia duodenalis from humans as assessed by an adhesion assay. Int J Parasitol. 1995;25:593-9.

59. Lemée V, Zaharia I, Nevez G, Rabodonirina M, Brasseur P, Ballet $\mathrm{JJ}$, et al. Metronidazole and albendazole susceptibility of 11 clinical isolates of Giardia duodenalis from France. J Antimicrob Chemother. 2000;46:819-21.

60. Boreham PF, Phillips RE, Shepherd RW. Altered uptake of metronidazole in vitro by stocks of Giardia intestinalis with different drug sensitivities. Trans R Soc Trop Med Hyg. 1988;82:104-6.

61. Townson SM, Upcroft JA, Upcroft P. Characterisation and purification of pyruvate:ferredoxin oxidoreductase from Giardia duodenalis. Mol Biochem Parasitol. 1996;79:183-93.

62. Argüello-García R, Cruz-Soto M, Romero-Montoya L, OrtegaPierres G. In vitro resistance to 5-nitroimidazoles and benzimidazoles in Giardia duodenalis: variability and variation in gene expression. Infect Genet Evol. 2009;9:1057-64.

63. Narikawa S. Distribution of metronidazole susceptibility factors in obligate anaerobes. J Antimirob Chemother. 1986;18:565-74.

64. Marczak R, Gorrell TE, Müller M. Hydrogenosomal ferredoxin of the anaerobic protozoon, Tritrichomonas foetus. J Biol Chem. 1983;258:12427-33.

65. Liu SM, Brown DM, O’Donoghue P, Upcroft P, Upcroft JA. Ferredoxin involvement in metronidazole resistance of Giardia duodenalis. Mol Biochem Parasitol. 2000;108:137-40.

66. Chapman A, Cammack R, Linstead D, Lloyd D. The generation of metronidazole radicals in hydrogenosomes isolated from Trichomonas vaginalis. J Gen Microbiol. 1985;131:2141-4.

67. Smith NC, Bryant C, Boreham PF. Possible roles for pyruvate:ferredoxin oxidoreductase and thiol-dependent peroxidase and 
reductase activities in resistance to nitroheterocyclic drugs in Giardia intestinalis. Int J Parasitol. 1988;18:991-7.

68. Ellis JE, Wingfield JM, Cole D, Boreham PF, Lloyd D. Oxygen affinities of metronidazole-resistant and -sensitive stocks of Giardia intestinalis. Int J Parasitol. 1993;23:35-9.

69. Leitsch D, Burgess AG, Dunn LA, Krauer KG, Tan K, Duchêne M, et al. Pyruvate:ferredoxin oxidoreductase and thioredoxin reductase are involved in 5-nitroimidazole activation while flavin metabolism is linked to 5-nitroimidazole resistance in Giardia lamblia. J Antimicrob Chemother. 2011;66:1756-65.

70. Dan M, Wang AL, Wang CC. Inhibition of pyruvate-ferredoxin oxidoreductase gene expression in Giardia lamblia by a virusmediated hammerhead ribozyme. Mol Microbiol. 2000;36:447-56.

71. Dunn LA, Burgess AG, Krauer KG, Eckmann L, Vanelle P, Crozet $\mathrm{MD}$, et al. A new-generation 5-nitroimidazole can induce highly metronidazole-resistant Giardia lamblia in vitro. Int J Antimicrob Agents. 2010;36:37-42.

72. Nillius D, Müller J, Müller N. Nitroreductase (GINR1) increases susceptibility of Giardia lamblia and Escherichia coli to nitro drugs. J Antimicrob Chemother. 2011;66:1029-35.

73. Müller J, Schildknecht P, Müller N. Metabolism of nitro drugs metronidazole and nitazoxanide in Giardia lamblia: characterization of a novel nitroreductase (GINR2). J Antimicrob Chemother. 2013;68: 1781-9. The role of nitroreductase $\mathbf{2}$ as metronidazole resistance determinan.

74. Tejman-Yarden N, Millman M, Lauwaet T, Davids BJ, Gillin FD, Dunn L, et al. Impaired parasite attachment as fitness cost of metronidazole resistance in Giardia lamblia. Antimicrob Agents Chemother. 2011;55:4643-51.

75. Müller M, Gorrell TE. Metabolism and metronidazole uptake in Trichomonas vaginalis isolates with different metronidazole susceptibilities. Antimicrob Agents Chemother. 1983;24:667-73.

76. Yarlett N, Yarlett NC, Lloyd D. Metronidazole-resistant clinical isolates of Trichomonas vaginalis have lowered oxygen affinities. Mol Biochem Parasitol. 1986;19:111-6.

77. Kulda J. Trichomonads, hydrogenosomes and drug resistance. Int J Parasitol. 1999;29:199-212.

78. Rasoloson D, Vanacova S, Tomkova E, Razga J, Hrdy I, Tachezy J, et al. Mechanisms of in vitro development of resistance to metronidazole in Trichomonas vaginalis. Microbiology. 2002;48:2467-77.

79. Leitsch D, Drinić M, Duchêne M. Down-regulation of flavin reductase and alcohol dehydrogenase-1 (ADH-1) in metronidazole- resistant isolates of Trichomonas vaginalis. Mol Biochem Parasitol. 2012;183:177-83.

80. Meingassner JG, Thurner J. Strain of Trichomonas vaginalis resistant to metronidazole and other 5-nitroimidazoles. Antimicrob Agents Chemother. 1979;16:254-7.

81. Leitsch D, Janssen BD, Kolarich D, Johnson PJ, Duchêne M. Trichomonas vaginalis Flavin reductase 1 (FR1) and its role in metronidazole resistance. Mol Microbiol. 2014;91: 198-208.

82. Müller J, Ley S, Felger I, Hemphill A, Müller N. Identification of differentially expressed genes in a Giardia lamblia WB C6 clone resistant to nitazoxanide and metronidazole. J Antimicrob Chemother. 2008;62:72-82.

83. Upcroft J, Mitchell R, Chen N, Upcroft P. Albendazole resistance in Giardia is correlated with cytoskeletal changes but not with a mutation at amino acid 200 in beta-tubulin. Microb Drug Resist. 1996;2:303-8.

84. Jiménez-Cardoso E, Eligio-García L, Cortés-Campos A, FloresLuna A, Valencia-Mayoral P, Lozada-Chávez I. Changes in betagiardin sequence of Giardia intestinalis sensitive and resistant to albendazole strains. Parasitol Res. 2009;105:25-33.

85. Paz-Maldonado MT, Argüello-García R, Cruz-Soto M, MendozaHernández G, Ortega-Pierres G. Proteomic and transcriptional analyses of genes differentially expressed in Giardia duodenalis clones resistant to albendazole. Infect Genet Evol. 2013;15:10-7.

86. Beech RN, Skuce P, Bartley DJ, Martin RJ, Prichard RK, Gilleard JS. Anthelmintic resistance: markers for resistance, or susceptibility? Parasitology. 2011;138:160-74.

87. Docampo R, Mason RP, Mottley C, Muniz RP. Generation of free radicals induced by nifurtimox in mammalian tissues. J Biol Chem. 1981;256:10930-3.

88. Bénéré E, da Luz RA, Vermeersch M, Cos P, Maes L. A new quantitative in vitro microculture method for Giardia duodenalis trophozoites. J Microbiol Methods. 2007;71:101-6.

89. Sterk M, Müller J, Hemphill A, Müller N. Characterization of a Giardia lamblia WB C6 clone resistant to the isoflavone formononetin. Microbiology. 2007;153:4150-8.

90. Lauwaet T, Andersen Y, Van de Ven L, Eckmann L, Gillin FD. Rapid detachment of Giardia lamblia trophozoites as a mechanism of antimicrobial action of the isoflavone formononetin. J Antimicrob Chemother. 2010;65:531-4.

91. Harris JC, Plummer S, Lloyd D. Antigiardial drugs. Appl Microbiol Biotechnol. 2001;57:614-9. 